Igor Vidić

HEP Trade Ltd

igor.vidic@hep.hr

Matija Melnjak

HEP Trade Ltd

matija.melnjak@hep.hr

Davor Bošnjak

HEP Trade Ltd

davor.bosnjak@hep.hr

\title{
How COVID-19 lockdown has impacted demand curves of Croatia and the surrounding countries
}

\section{SUMMARY}

Electrical energy is a specific commodity because it can't be stored in significant quantities, so accurate day-ahead forecasting of total consumption plays a crucial role in stable operation of the whole power system. In order to maintain the adequacy, power generation and electricity consumption have to be constantly in a balance.

Electricity demand curve is very sensitive and vulnerable to a lot of different factors that can be categorized in several main groups that include social, stochastic and weather dependent factors.

In condition of global pandemic caused by COVID 19, prediction of total consumption is even more challenging task. New restrictive rules, that completely changed behavior of consumers, their daily routine and habits, have been adopted in most of the European countries. Hence, this lockdown restrictive measures affected the volume of electricity consumption and the shape of demand curves as well.

This paper analyzes some of the cases with very variable electricity load, due to volatile households' behavior, on cases of Croatia and countries in the region. Additionally, results are compared with the electricity load of Italy and Sweden whose economy and industry are well developed. Consumption of Sweden was interesting to observe because of its totally different approach of mitigating corona virus, without lockdown restrictions.

\section{KEY WORDS}

corona virus, COVID-19, electricity load curve, electricity demand forecasting, lockdown restrictions

\section{INTRODUCTION}

This research aims to investigate the impact of the COVID-19 on the shape of Croatian load curve and the consumption of electricity in general. Furthermore, a brief analysis of a situation in the region was carried out and the results will be presented.

Many people claim that the corona crisis in Italy and Europe escalated after the Champions League match in Milano on $19^{\text {th }}$ of $\mathrm{Fe}$ bruary 2020 where Atalanta hosted Valencia. Suddenly, a few days after that match Italy became, by far the most affected European country and the city of Bergamo one of its worst-hit towns. The first case of COVID-19 infection in Croatia was confirmed in the last week of February, precisely on $25^{\text {th }}$ of February 2020. As the patient number zero was marked a young guy who attended that football match in Milano. As time was passing, the number of people infected by the coronavirus disease was growing daily, but fortunately, the exponential rise of new cases was mitigated [1].
Consequently, the National crisis management was set up to fight the coronavirus and slow down the spreading of the virus among the population [2]. In cooperation with the government some new rules, that completely changed the way most of the citizen's life, have been adopted.

These rules and restrictions incorporated not only the suspension of lessons in all schools and all universities but also temporarily end of work in all kindergartens. Furthermore, employers were forced to enable working from home to most of their employees, if it is anyhow possible. Otherwise, they had to reduce the number of people sitting in the office at the same time. All public meetings, public occasions, sports competitions, trade fairs, and gatherings for the purpose of religion were strictly forbidden. In addition to this, service activities that are not essential for the functioning of the community were also stopped. Hence all museums, theaters, disco clubs, libraries, gyms and fitness centers, bars, hairdressers closed their doors. Permission to work but with strict rules had only supermarkets, bakeries, restaurants with food deliveries, and pharmacies. Furthermore, all kinds of public, city, and intercity transport were suspended. 
Living under these lockdown restrictions completely changed our daily routines and past habits, thus we had to forget the life we had before. Therefore, it is likely to expect significant changes in electricity consumption.

This research focuses on gathering and analyzing electricity consumption data for Croatia and neighboring countries during the COVID-19 pandemic.

\section{ELECTRICITY DEMAND FORECASTING}

Electricity load forecasting is a complex task which incorporates a variety of variables that directly or indirectly affect the demand for an electricity [3] Electric energy consumption is the actual energy demand in the real time made on existing electricity supply [4].

Electricity consumption is a vital part of economic activity and an irreplaceable part of our daily needs. Thus, electricity load profile ([5], [6], [7]) reflects "an electrical activity of the hearth of a nation, region or individual customer" like an ECG [8]. It surely represents holistic pulse of customers at an observed moment.

Accurate planning of the day-ahead electricity load can also significantly help system operators with less activation of ancillary services in the rea time. Thus, it is important to have a reliable method for electricity consumption prediction and consider time decomposition which includes long, medium and short-term framework [9] . A variety of factors mentioned in [10] in long-term and medium-term load pattern forecasting, such as population, economic development, climate, etc. influence the total electricity load of one country. There are plenty of existing load forecasting methods that can be used for a day-ahead consumption planning. An overview and review of such electricity consumption planning methods were given in [11]. Generally, models could be divided into intelligent non-linear models that incorporate advanced technologies such as Artificial Neural Network ([12],[13]), grey prediction models [10], and statistical analysis models. Moreover, there are also a variety of other hybrid models. One of such developed models is presented in this chapter. This model consists of factors divided into three key categories: weather dependent factors related to the load, social factors connected to the load, and stochastic factors that affect load changes [14]. This is presented by the following equation:

$$
P(t)=\alpha^{*} P_{w}(t)+\beta^{*} P_{s}(t)+\gamma
$$

Where:

$$
\begin{array}{ll}
\text { - } & P(t)-\text { total electricity load in a certain period } \\
\text { - } & P_{w}(t) \text { - weather dependent factor of the total load } \\
\text { - } & P_{s}(t) \text { - coefficient correlated with the weather dependent factor } \\
\text { - } & \beta-\text { coefficient correlated with social dependent factor } \\
\gamma-\text { constant for estimating stochastic load changes }
\end{array}
$$

Furthermore, each of these variables, which behave like independent or partly dependent functions is then further decomposed and analyzed in individual sub-functions. For example, a weather dependent factor incorporates air temperature, wind speed and direction, cloudiness as well as type and intensity of a precipitation. Furthermore, there is also a humidity (dew point) which affects a load curve in cases of high and low temperatures.

This is presented in following equation:

$P_{w}(t)=\alpha_{1}{ }^{*} T(t)+\alpha_{2}{ }^{*} C(t)+\alpha_{3}{ }^{*} W s(t)+\alpha_{4}{ }^{*} W d(t)+\alpha_{5}{ }^{*} R t(t)+\alpha_{6}{ }^{*} R i(t)+\alpha_{7}{ }^{*} H(t)$

\section{Where:}

$$
\begin{aligned}
& \bullet \\
& \bullet \\
& \bullet \\
& \bullet \\
& \bullet \\
& \bullet \\
& \bullet \\
& \bullet
\end{aligned}
$$

$P_{w}(t)$ - weather dependent factor of the total load

$T(t)$ - external temperature dependent factor

$C(t)$ - cloudiness dependent factor

$W s(t)$ - wind speed dependent factor

$W d(t)$ - wind direction dependent factor

$R t(t)$ - precipitation type dependent factor

$R i(t)$ - precipitation intensity dependent factor

$H(t)$ - humidity (dew point) dependent factor

$\alpha_{1} \alpha_{2}, \alpha_{3}, \alpha_{4} \alpha_{5}, \alpha_{6} \alpha_{7}$ - coefficients for estimating load changes

with correspondent weather dependent factors

This example is just one of the multiple ways of forecasting electricity consumption that illustrates its complexity. Such challenge can be described like forecasting both "nature" and "society" during a timeline which affect the shape and values of the forecasted load curve. Naturally, in countries with higher industrial development and lower share of households' electricity consumption, load forecasting can be considered somewhat easier since a household consumption can be very fluctuating and unpredictable. An example of such a country where a load forecasting is a tremendous challenge is Croatia where the majority of the electricity demand consists of households. Thus, when forecasting the electricity demand curve a special consideration for social factors (holidays, weekends, semi-working days, public events, lockdown restrictions, etc.) has to be taken into account. Even the slightest weather or social changes can significantly impact the total load curve. The main analysis of this paper considers the impact of COVID-19 and corresponding lockdown measures on the electricity demand curve and how to read its data. Such pandemic has significantly affected behavior of demand curves and it has to be taken into account while analyzing realised electricity load curves during such period and forecasting electricity load curves in ever similar period in any stage in the future.

\section{ANALYSIS OF ELECTRICITY DEMAND CURVES}

This chapter will describe and analyze gathered data for Croatia and neighboring countries in terms of electricity consumption as well as give an overview of restrictive lockdown measures and how they affect overall electricity consumption. The analysis will be carried out and results compared to the previous historic data in the following subsections. In addition, the analyses was expanded to the case of Sweden which, although is not in the region with others, is an interesting case to compare with due to its complete opposite approach in national strategy of not imposing the restrictive lockdown measures.

Period of analysis is 14 weeks and exact periods of each week are presented in Table 1.

Table 1. Analyzed period

\begin{tabular}{|c|c|c|}
\hline & 2019. & 2020 \\
\hline Week 1 & $25.2 .-3.3$. & $24.2 .-1.3$. \\
\hline Week 2 & $4.3 .-10.3$. & $2.3 .-8.3$. \\
\hline Week 3 & $11.3 .-17.3$. & $9.3 .-15.3$. \\
\hline Week 4 & $18.3 .-24.3$. & $16.3 .-22.3$ \\
\hline Week 5 & $25.3-31.3$. & $23.3 .-29.3$ \\
\hline Week 6 & $1.4 .-7.4$. & $30.3 .-5.4$. \\
\hline Week 7 & $8.4 .-14.4$. & $6.4 .-12.4$. \\
\hline Week 8 & $15.4 .-21.4$. & $13.4 .-19.4$. \\
\hline Week 9 & $22.4 .-28.4$. & $20.4 .-26.4$. \\
\hline Week 10 & $29.4 .-5.5$. & $27.4 .-3.5$. \\
\hline Week 11 & $6.5 .-12.5$. & $4.5 .-10.5$. \\
\hline Week 12 & $13.5 .-19.5$. & $11.5 .-17.5$. \\
\hline Week 13 & $20.5 .-26.5$. & $18.5 .-24.5$. \\
\hline Week 14 & $27.5 .-2.6$. & $25.5 .-31.5$. \\
\hline
\end{tabular}

Table 2. Total number of new weekly confirmed COVID-19 cases

\begin{tabular}{|c|c|c|c|c|c|c|c|}
\hline \multicolumn{2}{c}{ Italy } & \multicolumn{1}{c}{ Croatia } & Hungary & \multicolumn{1}{c}{ Slovenia } & Bosnia & Serbia & Sweden \\
\hline Week 1 & 1557 & 7 & 0 & 0 & 0 & 0 & 13 \\
\hline Week 2 & 5686 & 5 & 8 & 16 & 2 & 1 & 189 \\
\hline Week 3 & 16605 & 36 & 31 & 237 & 19 & 54 & 829 \\
\hline Week 4 & 35158 & 187 & 128 & 189 & 141 & 133 & 874 \\
\hline Week 5 & 38551 & 478 & 280 & 321 & 251 & 553 & 1794 \\
\hline Week 6 & 31259 & 469 & 297 & 258 & 368 & 1167 & 3130 \\
\hline Week 7 & 27415 & 418 & 714 & 191 & 292 & 1722 & 3653 \\
\hline Week 8 & 22609 & 271 & 526 & 123 & 267 & 2688 & 3902 \\
\hline Week 9 & 18703 & 159 & 599 & 72 & 248 & 1724 & 4255 \\
\hline Week 10 & 13042 & 66 & 452 & 38 & 358 & 1422 & 3677 \\
\hline Week11 & 8353 & 91 & 249 & 16 & 212 & 650 & 4005 \\
\hline Week 12 & 6365 & 39 & 251 & 6 & 161 & 496 & 3821 \\
\hline Week 13 & 4423 & 18 & 221 & 2 & 97 & 549 & 3316 \\
\hline Week 14 & 3161 & 2 & 120 & 6 & 118 & 253 & 4083 \\
\hline
\end{tabular}


Along with weekly total load data, the number of weekly COVID-19 positive cases has been gathered for each of analyzed region. Table 2 presents data of new weekly confirmed COVID-19 cases for each of the analyzed region.

However, due to a vast difference in sizes of countries, and thus a much higher number of confirmed cases for larger countries, for purpose of this analyses it is better to look at number of cases per 10000 residents.

\section{New weekly COVID-19 cases per 10000} residents

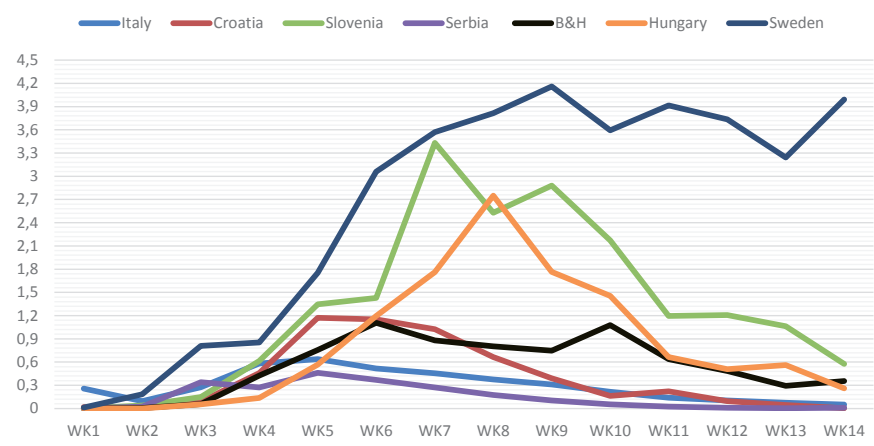

Figure 1 Number of new weekly COVID-19 positive cases per 10000 residents for each respective region

As seen in Figure 1. Sweden has the highest rate of COVID-19 positive cases per 10000 residents and their trend from week 7 to week 14 is not declining as it is the case for other countries in this analysis. The main reason for this is that Sweden is the only European country that decided to take a different approach in the battle with the COVID-19 pandemic. They decided against the majority of restrictive measures or a complete lockdown that was introduced in other countries. Instead, they decided to try to overcome the pandemic by acquiring a herd immunity effect. Considering their specific approach, it is very interesting to include Sweden in the total load analyses and comparison with the rest of the countries in the region.

\subsection{ELECTRICITY DEMAND OF CROATIA}

Forecasting the load curve of Croatia is a challenging task. As there is a significant lack of industry, compared to the leading European countries, the highest share of the load comes from the end-consumers and households. Thus, the forecasting of electricity load curves has a wide range of options due to the stochastic and fluctuating behavior of households' consumption as well as external conditions such as weather and socia impact. Observation of Croatian total load was made for 14 weeks starting from the last week of February to the end of May. During the first three observed weeks, there were no signs of the impact of corona virus on the demand curve. Despite the COVID-19's presence in Croatia, there weren't any new rules or restrictions that would change people's lives and daily habits. Life was as usual as before, but things started to change in the week 4 (16.3.2020.-22.3.2020.) when the National crisis management decided to close all schools, universities, and kindergartens to mitigate the spreading of corona virus. From Thursday 19.3.2020., all public events and gatherings were forbidden. Only necessities such as supermarkets, pharmacies, and restaurants with food delivery options have had working permits. All other service activities had temporarily locked their doors. From the Sunday of week 4 (22.3.2020.) all kinds of public transport were stopped. Some of these restrictive rules, such as suspending tram and train traffic closing the majority of shops and markets, were an obvious cause for the decrease in the electricity consumption. On the other hand, it is hard to estimate how the school closing has affected electricity demand because all pupils and students had to follow the lectures using TV, tablets, and computers.

The demand curve shows that the total load fell off or decrease in regards to the previous week when restrictions haven't been yet adopted. Contrary to what might be expected, the total load of the fifth week has increased. However, it is mostly due to harsh weather conditions that incorporate extreme coldness for this period of the year, snow, and wind during most of the week which can be seen in Figure 3 and Figure 4. On the demand curve, it can be noticed that even though the temperatures were very low, electricity consumption fell in mornings hours, and increase significantly later, around noon, during afternoon and in the evening. The shape of the demand curve had completely changed and the daily peak was almost as high as the evening peak which is uncharacteristic to previous historic data. In nearly all hours (exception of the morning), consumption was higher than the one in the previous weeks, which can be interpreted by the fact that people woke up later and postponed their usual morning activities and habits since most of them worked from home. In certain hours tota load was similar to the period before restrictions. In the sixth observed week, temperatures were also under average, however, the total load has decreased. Summertime calculation (Day-light saving time) led to reaching the evening peak in the twenty-first hour, and more daylight affected consumption too.

During the seventh week, the consumption continued to fall, and it was nearly 32 GWh lower than the previous week. This has marked the highest difference of realized load between two continuous weeks which can be explained by the fact that it was Easter week, and the holiday has significantly impacted total load. Monday of eights' week was a holiday as well, and the total load was also lower than the previous week. However, the demand curve had almost the same shape. It was slightly translated in the downwards direction.

The ninth week was very similar to the previous with an insignificant rise in total consumption. Restrictive rules, adopted during the lockdown, have been cleared starting from week ten. At the beginning of week ten, supermarkets started to reopen, except for the ones in shopping centers. Furthermore, certain services activities, which don't require close contact between people have also started to reopen along with public transport. However, the lowest consumption was achieved in this week, and from that point, the load started to slowly recover in the upcoming weeks. From the eleventh week, it was allowed for all services activities to reopen their doors (hairdressers, barbers, beauticians, etc.). The last phase of restrictions clearing started in week twelve, when shopping centers, bars, and restaurants were reopened. In the last three weeks, the shape of the demand curve changed mostly in the afternoon „gap“ when the total load has risen. In addition, this evening consumption reached a peak in the twenty-second hour.

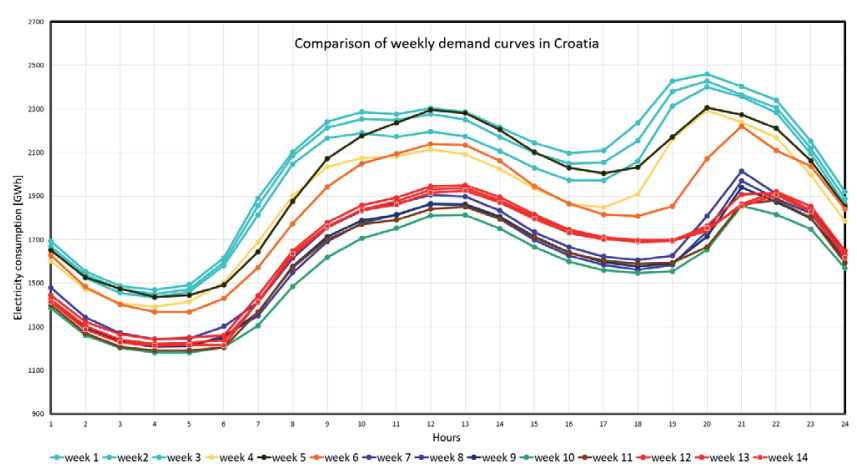

Figure 2 Average weekly demand curves of Croatia

Electricity consumption, in general, is mostly dependent on external conditions such as weather. Some of these parameters are, as already mentioned in the Chapter 2, air temperatures, cloudiness, precipitation, wind speed, wind direction and humidity. A comparison of all of these parameters would be too complicated and nearly impossible, hence, only the air temperature will be taken into consideration in future analysis and comparison with previous historical data.

Following figures (3-6), present average daily temperatures in cities of Zagreb and Split during 14 weeks (98 days) in the year 2019 and 2020.

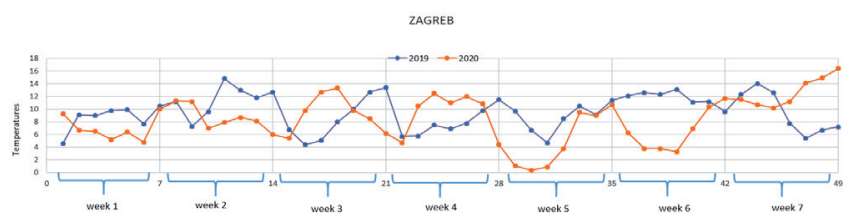

Figure 3 Average air temperature in Zagreb during first seven weeks

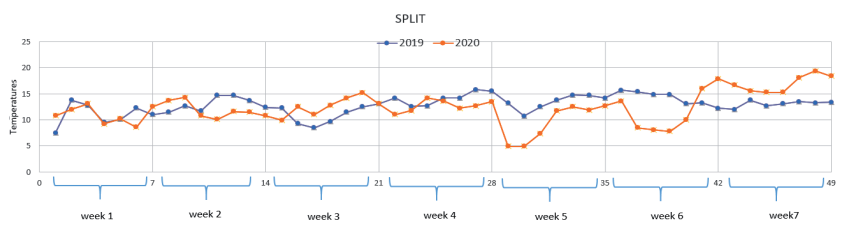




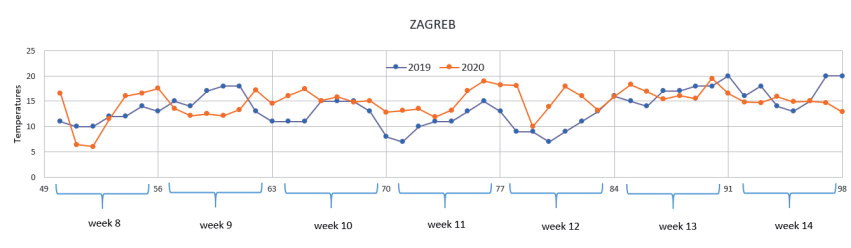

Figure 4 Average air temperature in Split during first seven weeks

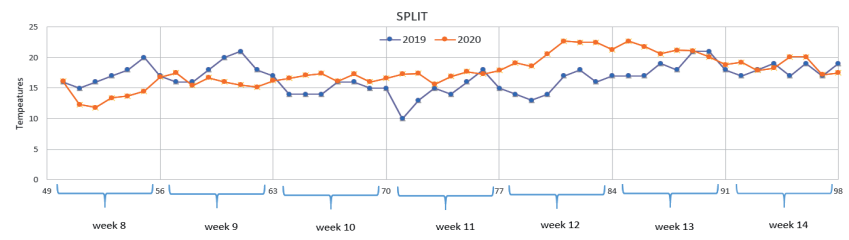

Figure 5 Average air temperature in Zagreb during second seven weeks

Figure 6 Average air temperature in Split during second seven weeks

Almost in all weeks during the lockdown the total load has decreased in regards to the same period in the previous year which can be seen in $\mathrm{Fi}$ gure 7 . Only in week five, electricity consumption has risen by $1,57 \%$ in comparison with the previous year, even though the new restrictive rules have been adopted. The main reason was certainly weather conditions and very low temperatures as it is shown in Figure 3 and Figure 4. The impact of new restrictive measures on electricity consumption can be seen in a total load of week six when temperatures were also lower than the ones a year ago, but the total load fell by $2,44 \%$. After the restrictions have been released, the total load started to slowly recover. However, it was almost insignificant. There was still a big difference between the same period of

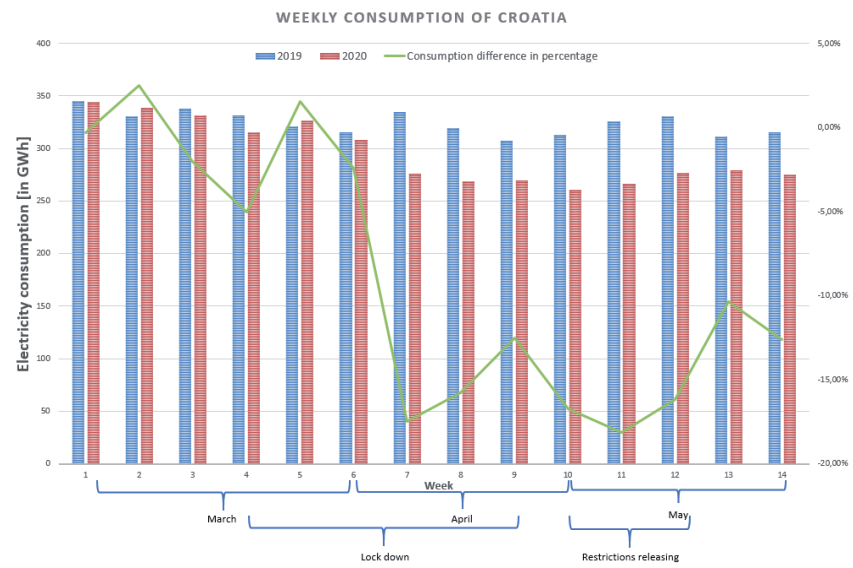

the previous year because previous May has been much colder as it can be seen in Figure 4 and Figure 5.

Figure 7 Comparison of weekly total load of Croatia for 2019 and 2020

\subsection{ELECTRICITY DEMAND OF NORTHERN ITALY}

North Italy was the worst-hit region of the country. Coronavirus spread rapidly after the Champions League match between Atalanta Bergamo and Valencia that was held in Milano, on the $19^{\text {th }}$ of February. It is believed that it is the main reason why Bergamo has become the epicenter of the pandemic. North Italy is the most developed part of the country and it incorporates the following regions: Val D'Aosta, Piemonte, Liguria, Lombardia, Trentino, Veneto, Friuli Venezia Giulia, and Emilia Romagna. A significant contribution to a total load of North Italy is the industry and it is a major reason why electricity consumption decreased significantly during the lockdown. Figure 8 shows that the total load has not instantly decreased within the first two weeks of COVID-19 appearance in Northern Italy. However, as the number of confirmed COVID-19 cases grew, restrictive measures were introduced. Moreover, the downwards trend of total load continued from week 3 to week 6 where it reached its minimum with roughly $35 \%$ of the total weekly load decrease in comparison with the previous year. Furthermore, week 7 in 2020 includes Good Friday and
Easter Sunday holidays, while in 2019 such week was in week 8. These holidays in most of Europe significantly influence the shape of the load curve and Italy especially. As can be seen in , from weeks 7 to 14, the total weekly load has begun to recover reaching roughly $10 \%$ of the total load decrease in week 14. However, this assertion has to incorporate influence of different dates and weeks of Eastern holidays when we make conclusions about exact "tipping point" when and why the load curve started to ascend.

According to Instituto Superiore di Sanita, almost $80 \%$ of the total confirmed cases by $3^{\text {rd }}$ of June 2020 were from the regions listed above. Thus,

WEEKLY CONSUMPTION OF NORTHERN ITALY

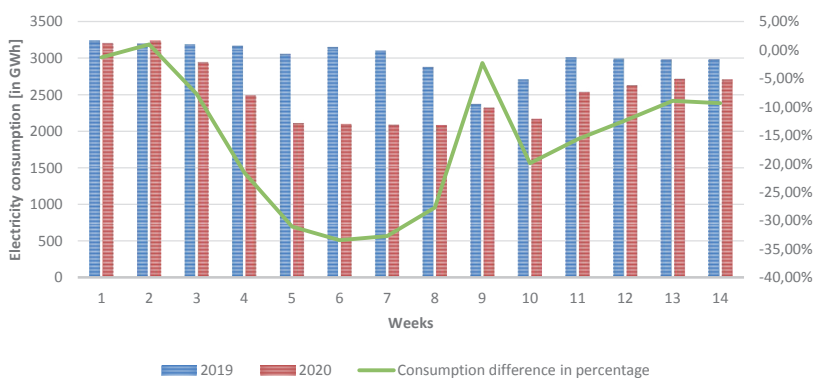

this paper focuses on North Italy rather than the entirety of Italy. Due to the strong economy and developed industry, the recovery of the total load is significantly faster in comparison with other regions analysed in this paper.

Figure 8. Comparison of weekly total load of North Italy for 2019 and 2020

\subsection{ELECTRICITY DEMAND OF SLOVENIA}

Similar to the case of Croatia, Slovenia decided to tackle the COVID-19 pandemic with strict restrictions and lockdown. The first cases appeared in roughly the same period, and as previously shown in Figure 1. Slovenia had one of higher rates of COVID-19 infections per 10000 residents.

\section{WEEKLY CONSUMPTION OF SLOVENIA}

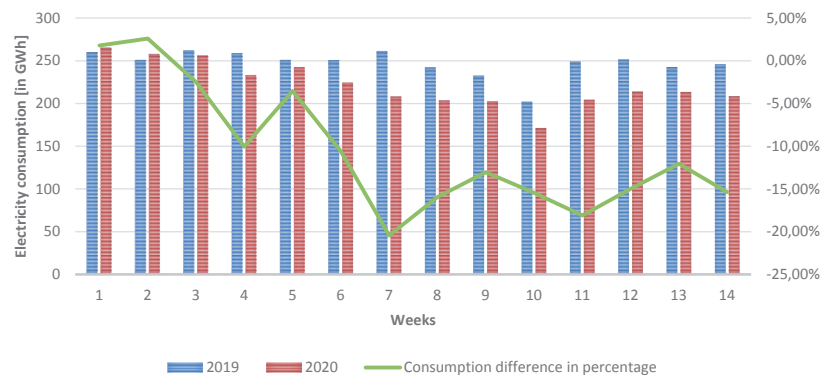

However, with their governmental measures, they managed to control and stop further growth of cases. From week 7 and on, their measures proved efficient, and the decline in newly infected people has started.

Figure 9 Comparison of weekly total load of Slovenia for 2019 and 2020

Figure 9 presents a comparison of the Slovenian total load in 2019 and 2020. A clear impact of COVID-19 can be seen in the decrease of the total load which has peaked in week 7. A peak difference between these two years is roughly $20 \%$ of the total load. This is also the period where the number of new cases has peaked. As the pandemic has been put under control, from week 8 and on, the total load has started to slowly recover. However, their recovery is at a moderate rate and the aftermath of COVID-19 is still present in significantly lower consumption (roughly 15\% lower).

\subsection{ELECTRICITY DEMAND OF SERBIA}

Although the first cases of COVID-19 in Serbia arose in a similar period as the rest of the region, the first 6 weeks marked the total load increase in comparison with the previous year. One of the reasons for this is that their national strategy has decided to wait with restrictive measures and lockdown, and the weather impacted the total load. However, once the number of cases has significantly risen, they introduced strict restrictions 


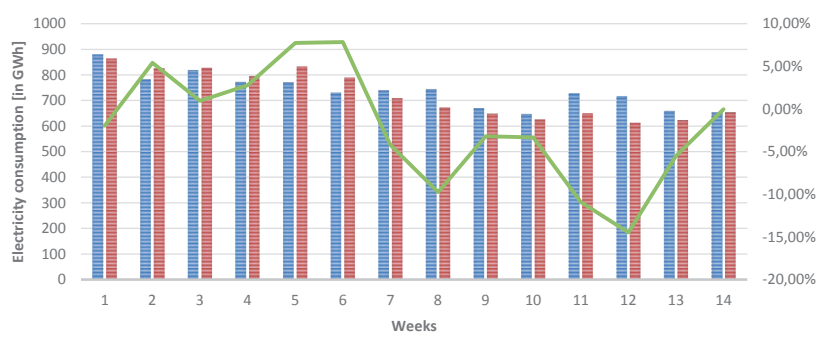

=2019 2020 Consumption difference in percentage

and a complete lockdown. Furthermore, a police hour has been enforced during some weekends where people were not allowed to leave their homes unless it was a must. This can be seen in Figure 10 where their total load has decreased by nearly $10 \%$ in week 8 . From this point on, their load was slightly lower in comparison with the previous year.

Figure 10 Comparison of weekly total load of Serbia for 2019 and 2020

The case of Serbia shows signs of COVID-19 pandemic consequences on the total load, however, they are not as significant for the total load as the previously analyzed case of North Italy. Moreover, the analysis has not been as in-depth as the case of Croatia as the goal was to present overall total load data comparison.

\subsection{ELECTRICITY DEMAND OF HUNGARY}

The first cases of COVID-19 in Hungary appeared in the second analyzed week. In comparison with other countries in the region, the initial situation in Hungary appeared well as they counted one of the lowest amounts of COVID-19 cases in the first few weeks. Figure 1 graphically shows that they had one of the slowest starts in COVID-19 cases. However, the peak in new cases was also later than in other countries. Naturally, the restrictive measures were also implemented in a different time period from other countries. The situation is also translated into the total load curve. In the first three weeks, Hungary marked an increase in the total load in comparison with previous years. Moreover, as the number of cases grew and restrictive measures had been introduced, the decline of the total consumption had begun. Similar to the cases of Croatia and Slovenia, Hungary also

WEEKLY CONSUMPTION OF HUNGARY

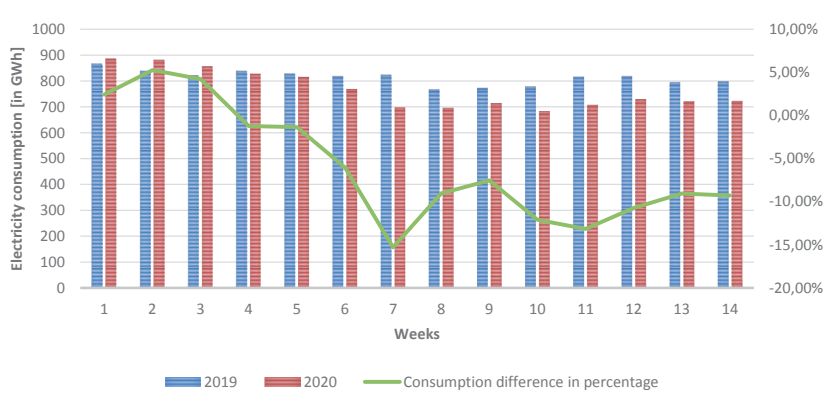

experienced the lowest total load in week 7. The total load had decreased by nearly $15 \%$ in comparison with the previous year. From this point on, the difference has been fluctuating but it has never recovered above the $7 \%$ decrease in the total load.

Figure 11 Weekly total load comparison of Hungary for 2019 and 2020.

The case of Hungary is similar to other analysed cases where the COVID-19 pandemic significantly decreased countries' total load due to restrictions.

\subsection{ELECTRICITY DEMAND OF BOSNIA AND HERZEGOVINA}

The case of Bosnia and Herzegovina is challenging to analyze. Despite other countries in the region marking economic and electricity consumption increase, Bosnia and Herzegovina marked a total load decrease even in weeks before the COVID-19 pandemic. Considering their total load decrease before the pandemic, it is hard to judge exactly how huge is the

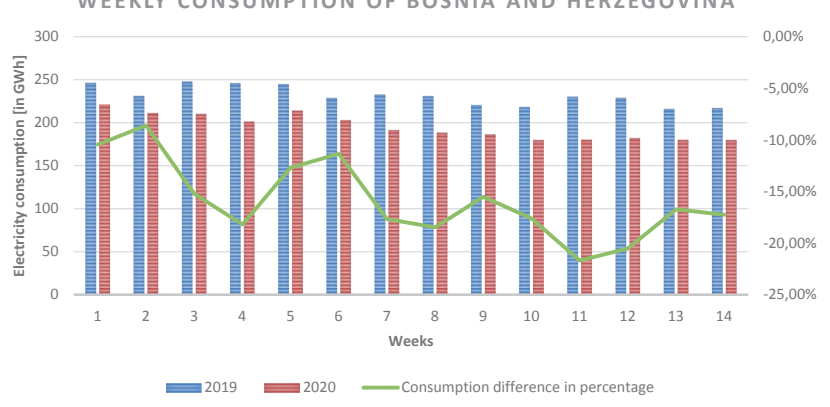

impact of COVID-19.

Data presented in Table 2. shows a similar trend between the number of cases in Bosnia and Herzegovina as in Croatia and Hungary. Interestingly, the number of weekly cases has not gone above 1.25 per 10000 residents which is the lowest in the region, besides Italy.

Figure 12 Weekly total load comparison of Bosnia and Herzegovina for 2019 and 2020.

Figure 12 shows a total load decrease in all of the 14 analyzed weeks which is not the case for any other country analyzed in this paper. The COVID-19 pandemic peaked between weeks 4 and 11, and the highest decrease in the total load was in week 11 (20\% decrease in relation to the previous year). Generally, their load is very fluctuation and there are no signs of its recovery in this analyzed period.

\subsection{Electricity demand of Sweden}

As previously mentioned at the beginning of Chapter 3, Sweden decided to take a different approach in battle with this pandemic. Rather than introducing serious restrictive measures and enforcing a lockdown, it was decided that the national strategy was to try to acquire the herd immunity effect. Naturally, this meant that the number of COVID-19 positive patients was much higher in comparison with other countries which can be seen in Figure 1. Contrary to other observed countries, the number of infected people has not declined in upcoming weeks either which is an expected

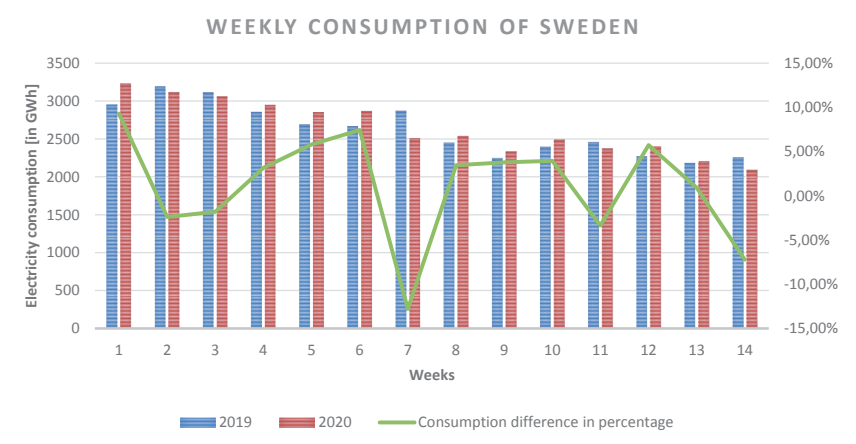

outcome due to the lack of restrictive measures.

However, this strategy meant that the Swedish economy and industry would not take such a hit as other countries observed in this paper. Thus, it is expected that the total load should not massively decline either.

\section{Figure 13 Weekly total load comparison of Sweden for 2019. and 2020}

As seen in Figure 13 the total load of Sweden was very similar in the majority of weeks for the years 2019 and in 2020. Undoubtedly, some differences in the total load are always going to exist due to a vast variety of external factors. However, when compared to other analyzed countries in this paper, there is no significant decline besides week 7 . The main reason for this is the temperatures in Sweden in 2019 were extremely low in that period. Temperature data is presented in Figure 14 where the average weekly temperature in 2019 was around 1 Celsius degree while the temperature in 2020 was around 8 Celsius degree which is more standard for that period of the year. Consequently, a total load of week 7 in 2019 was significantly higher than it would have been with regular temperatures. Thus, the conclusion is that the main reason for the decline was not COVID-19 pandemic but the extreme weather conditions in the previous year. 

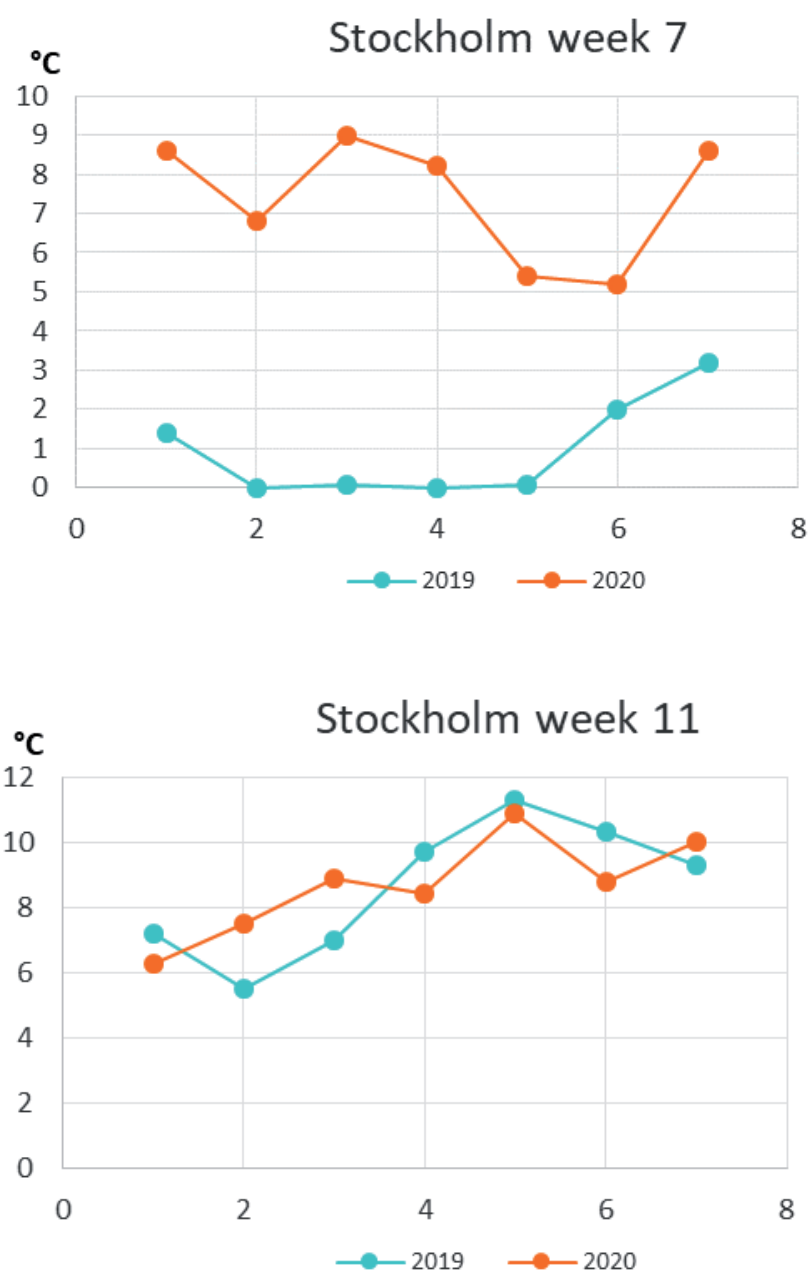

Figure 14 Temperature differences in week 7 and week 11 for Stockholm, Sweden.
Moreover, the total consumption has even increased in weeks almost twothirds of the weeks.

With Sweden's different approach, it can be seen that the total load has not been as affected during the pandemic as much as it was in other analyzed countries. Furthermore, judging from the total load, their economy and industry have not suffered either.

\section{RESULTS AND DISCUSSION}

Analysis and data provided in chapter 3 indicate how sensitive a total load of a country is. A variety of external factors significantly affects the consumers' behavior, and thus, the electrical energy consumption. This paper focuses on the social dependent factor connected to the load - COVID-19 pandemic.

The most in-depth analysis was provided for the case of Croatia which is characterized by a very volatile total load. Although the weather-dependent factor is important and cannot be completely neglected, a detailed analysis of it was not provided for cases besides Croatia.

Initially, this paper was meant to include only Croatia and its region (surrounding countries). However, the case of Sweden is extremely interesting and useful for comparison and evaluation of what affects the load the most.

Results indicate that the COVID-19 pandemic caused significant load decrease throughout Europe which was foremost in the period of harsh working restrictions or lockdowns. Cases of Croatia, North Italy, Slovenia, Hungary, and Serbia all suffered a significant load decrease in comparison with previous years. The period of first COVID-19 appearance was similar and each of these countries started to introduce restrictive measures.

A graphical display of the load difference of the three most interesting cases (Croatia, North Italy and Sweden) is provided in Figure 15. The highest load decrease was present in North Italy (up to $35 \%$ decrease in comparison with previous years), while Croatia, Slovenia, Hungary, and Serbia all experienced load decrease up to $15 \%$. This only further confirms how strong the industry of North Italy is in terms of the load consumption as it drastically decreased in the period of harsh restrictions and lockdown. On the other hand, it can also be seen that a load of North Italy also has started recover significantly faster than the load of any other analyzed country which once again supports the premise that the industry has a significant share in the total load. Nevertheless, it must not be forgotten the influ-

\section{Total load difference (in percentage) between 2019 and 2020 for every analyzed country}

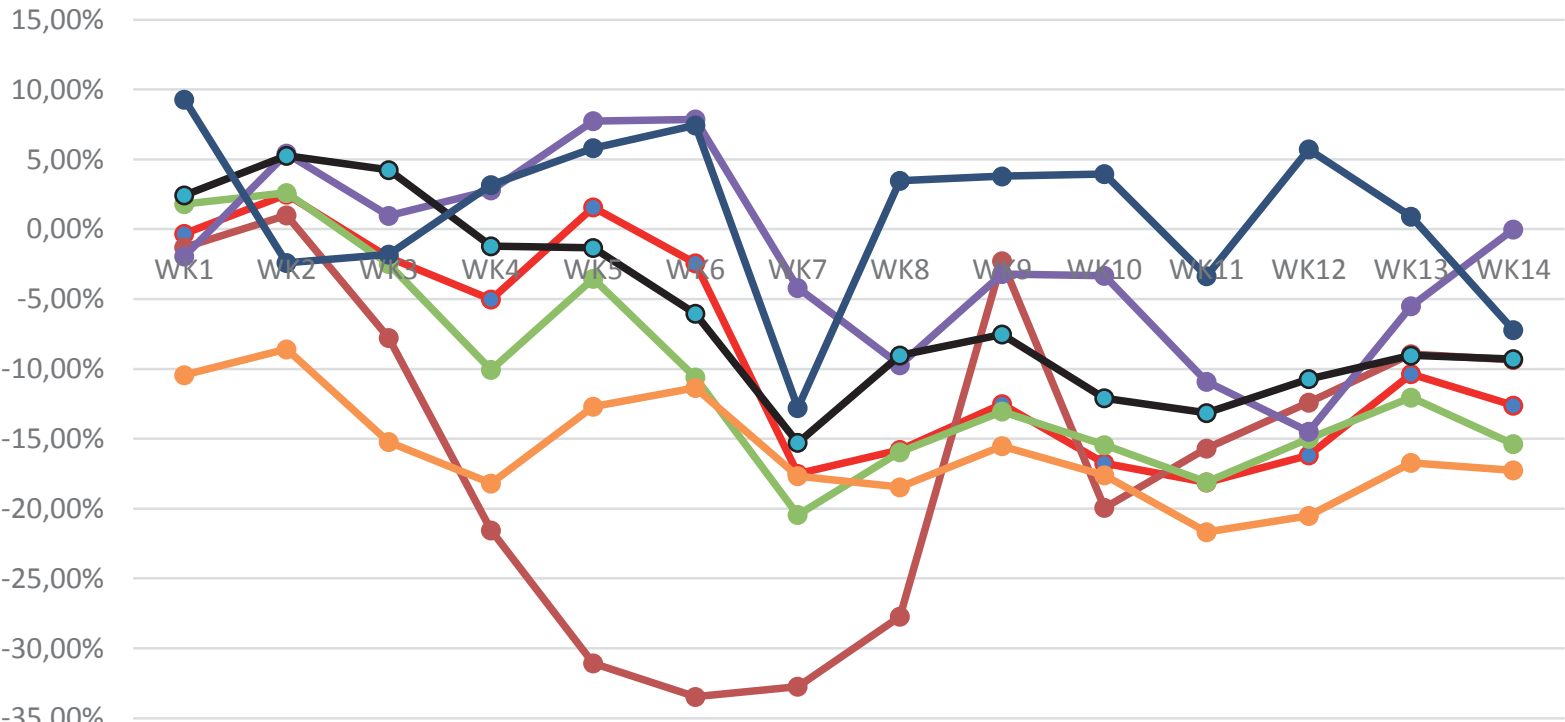

$-40,00 \%$

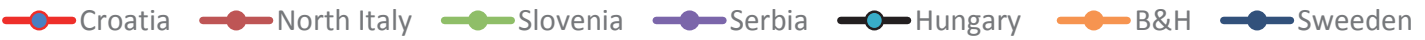

Figure 15 Comparison of total load differences between 2019. and 2020. for analyzed countries 
ence of different dates and weeks 7 and 8 in 2019 and 2020 which partly contribute to such steep decline and rise while comparing those two years.

The rest of the countries in the region have also started to recover in terms of load, however, it is at a more moderate rate. For the case of Bosnia and Herzegovina it is rather difficult to provide the right judgement. The results of the analysis imply that they have not suffered a significant load decrease in comparison with previous year which can be somewhat expected due to their poor relative industry contribution in total load share and partly due to different holidays during weeks 7 and 8 comparing most of other countries.. However, there are also uncertainties regarding the data.

Contrary to all of the 6 cases, Sweden has taken a completely different approach and introduced nearly no strict restrictions or lockdowns. Their total load is slightly fluctuating, and even increasing in some weeks. They had the highest number of COVID-19 positive cases (per 10000 residents) of all 7 analyzed countries, and their numbers have not been declining either. This indicates that it is not the number of COVID-19 positive cases that directly and significantly affect the load, but the governmental measures that affect it the most.

Generally speaking, it is expected that the higher number of positive cases would force countries in such restrictive measures and lockdowns which will result in a significant load decrease. However, the case of Sweden proved to us that there are exceptions and that some countries deploy different national strategies. Hence, it is of the utmost importance to keep in track with all national decisions regarding the restrictions, strategies, or lockdowns measures when planning a day-ahead (or further) load.

Moreover, the analysis shows that there are a lot of similarities between countries in the region, especially the ones with similar industrial development. It can be useful to observe their overall situation regarding the load trend, however, it is dangerous to blindly replicate their strategies as it was shown that load is extremely sensitive to all external factors.

\section{CONCLUSIONS}

This paper clearly shows the complexity of load forecasting and how the stochastic behavior of many influential factors can significantly contribute to the shape of realized load curve. Although there are usually many more examples of a weather influence on the load shape, this particular example teaches us all how social influence can also be important. Its significance is even more influential due to several reasons:

- $\quad$ Such events like sudden pandemic spread and adequate lockdown measures like in those several weeks usually cannot be foreseen in a year ahead, a quarter ahead, or even a month ahead load forecasting process and as a such could be marked as "Black Swan" effect [15].

- $\quad$ Nevertheless, such rare cases with significant impact, no matter how rare they are, must never be underestimated, especially if they have already occurred several times in the history [16] and when contemporary power systems, economic systems, and the whole globalized society are vulnerable [17], [18] to such outbreaks and potential lockdown measures

- $\quad$ Consequences of such measures jeopardize lives and livelihoods [19] of most of the electricity customers and if the statement that "emotion = energy in motion" [20] is applied to all customers in a portfolio or a country, an electricity demand response can be significant, sudden and sometimes even long-lasting, usually depending on the economic strength of the observed country [21] or customer's portfolio

- $\quad$ Such sudden electricity demand response has directly affected electricity prices [22]in Italy, there is an ongoing pandemic of coronavirus disease 2019 (COVID-19 and the whole electricity sector [23] as well as the entire power sector [24].

Therefore, this case can be very useful for understanding the sensitivity of the load curve, its importance in vital technical and economic processes in the globalized world, and necessary adjustments to the "new normal" conditions [25] which might last for some time in the forthcoming future and affect most of the electricity customers.

\section{REFERENCES}

[1] R. Čivljak, A. Markotić, and I. Kuzman "The third coronavirus epidemic in the third milenniepidemic in the third millennum: What's next?," Croat. Med doi: $10.3325 / \mathrm{cmi} .2020 .61 .1$

[2] S. Dodig, I. Čepelak, and I. Pavić, "AGE AND SARS-COV2 INFECTION," Acta Med Croat, vol. 74, pp. 135-144, 2020.

[3] H. Cho, Y. Goude, X. Brossat, and Q. Yao, "Modeling and forecasting daily electricity load curves: A hybrid approach," J. Am. Stat. Assoc., vol. 108, no. 501, pp. 7-21, 2013, doi: 10.1080/01621459. 2012.722900

[4] Wikipedia, "Electric energy consumption." 2020, Accessed: Sep. 10, 2020. [Online]. Available: https:// en.wikipedia.org/wiki Electric_energy_consumption,.

[5] Wikipedia, "Load profile." 2020, [Online]. Available: 2020, [Online]. Available: https://en.w

[6] HOPS, "Daily Load," 2020 https://www.hops.hr/en/dailyload (accessed Sep. 10, 2020).

[7] Entsoe, "Load data," 2020. https://transparency.entsoe.ew (accessed Sep. 10, 2020).

[8] Wikipedia, "Electrocardio- graphy." Accessed: Sep. 10, 2020. [Online] Available: https://en wikipedia Available: hipedia.org/wik

[9] E. Almeshaiei and H. Soltan, "A methodology for Electric Power Load Forecasting," Alexandria Eng. J., vol. 50, no. 2, pp. 137-144, 2011, doi: 10.1016/. aej.2011.01.015

[10] S. Ding, K. W. Hipel, and Y. guo Dang, "Forecasting China's electricity consumption using a new grey predictio model," Energy, vol. 149, pp. 314-328, 2018, doi: 10.1016/j. energy.2018.01.169.

[11] A. Khosravi, S. Nahavandi, D. Creighton, and D. Srinivasan, "Interval type-2 fuzzy logic systems for load forecasting: A comparative study," IEEE Trans. Power Syst., vol. 27, no. 3, pp. 1274-1282, 2012, doi: 10.1109/ TPWRS.2011.2181981.

[12] A. Khan et al., "Forecasting electricity consumption based on machine learning to improve performance: A case study for the organization of petroleum exporting countries (OPEC)," Comput. Electr. Eng., vol. 86, 2020, doi: 10.1016/ compeleceng.2020.106737.

[13] F. Kaytez, "A hybrid approach based on autoregressive integrated moving average and least-square support vector machine for long-term forecasting of net electricity concasting of net electricity con117200, 2020, doi: 10.1016/j. 117200, 2020, doi:
energy.2020.117200.

[14] Vitec Software Group, "Mode theory." Vitec, 2014, [Online]. Available: http://viteceducandi. com/.

[15] Wikipedia, "Black swan the ory." 2020, [Online]. Available: https://en.wikipedia.org/wiki/ Black_swan_theory.

[16] G. McGillivray, "Coronavirus is significant, but is it a true black swan event," 2020 . https:// theconversation.com/coronavirus-is-significant-but-is-it-atrue-black-swan-event-13667 (accessed Sep. 20, 2020).

[17] B. Gates, "The next outbreak? We're not ready," 2015 https://www.youtube.com/ watch?v=6Af6b wyiwl (accessed Sep. 20, 2020).

[18] T. D. S. D. Show, "Bill Gates on Fighting Coronavirus." https://www.youtube.com/ watch?v=iyFT8qXcOrM.

[19] U. N. D. Programme, "Socio-economic impact of $\mathrm{CO}$ VID-19." https://www.undp.org/ content/undp/en/home/coronavirus/socio-economic-impactof-covid-19.html.

[20] authenticityassociates "Emotions Are Energy: The bodymind connection and e-motion." https://www. authenticityassociates.com emotions-are-energy/.

[21] UNIDO, "Coronavirus: the economic impact," 2020. https:// www.unido.org/stories/co ronavirus-economic-impact10-july-2020.

[22] E. Ghiani, M. Galici, M. Mureddu, and F. Pilo, "Impact on Electricity Consumption and Market Pricing of Energy and Ancillary Services during Pandemic of COVID-19 in Italy," Energies, vol. 13, no. 13, p. 3357 , 2020, doi: $10.3390 /$ en13133357.

[23] IEA, "Covid-19 impact on electricity," 2020. [Online]. Available: https://www.iea.org/reports/ covid-19-impact-on-electricity.

[24] T. Bakovic, "The Impact of COVID-19 on the Power Sector, 2020.

[25] WHO, "COVID-19: 'new normal,"' 2020. https://www.who. int/westernpacific/emergencies/covid-19/information/ covid-19-new-normal. 